\title{
Through the Looking-Glass
}

\author{
Douglas Doucette
}

As we enter the final months of 2020, I suspect many of us have often felt this year like Alice going through the looking-glass in Lewis Carroll's 19th century fictional novel of fantastical travel and interactions with unlikely and unexpected characters. Most Canadians had not been through a pandemic and likely did not know what to expect when reports of COVID-19 and its imminent spread around the world began to circulate.

Our professional and personal lives have been irrevocably changed. The pandemic has caused nonprofit associations like the Canadian Society of Hospital Pharmacists (CSHP) to adjust office operations, member services, and programs. The CSHP Board and Branches reviewed their priorities, shifting focus onto select activities and deferring or suspending others, due to financial pressures exacerbated by the pandemic. The Canadian Journal of Hospital Pharmacy (CJHP) has been directly affected by recent cost-cutting measures. To maintain the high quality of the Journal and save on the cost of production, the CJHP has been reduced to 4 issues a year from 6 . In addition, the CJHP's submission system and publishing interface are being moved to a more efficient, cost-effective system that will streamline the Journal's workflow and offer readers more functionality.

These last few months, I have been reflecting on the experiences I have had during my 3-year term as a CSHP presidential officer. I had the opportunity to meet with key stakeholders in Health Canada, NAPRA, CAPSI, CPhA and more, which provided multifaceted insights into pharmacy and health care issues. As President, I responded to the media and other associations, as expected, but the topic and timing could not always be predicted. I am grateful to the office staff and fellow presidential officers for their support as I prepared for these interviews. There were circumstances I did not anticipate, however, such as the retirement of Myrella Roy, our long-serving Executive Director, shortly after I became President Elect. It was a privilege to work with Myrella for part of my term, but I was then charged with leading the task force to find her successor as CSHP's first Chief Executive Officer. It was an exciting time for the Board to select and for me to help orient the new CEO, Jody Ciufo, in 2019 to CSHP and hospital pharmacy in general. We worked together on the Strategy Towards Sustainability to chart our future as a national association. We also took time to celebrate the 50th anniversary of our Professional Practice Conference and reflect on how far our profession has come, in part, thanks to CSHP leadership and its members.

CSHP's Strategic Plan for 2020-2023 will soon (if it hasn't already) be released. It plots the path for improving member value and fiscal stability through defined, strategic priorities. As the voice of hospital pharmacy in Canada, CSHP has continued to show significant leadership on key advocacy issues in the areas of national pharmacare, mandatory reporting of serious adverse drug reactions, and the US importation of Canadian drugs. By late 2020, the recommendations from our Cannabis Task Force and Pharmacy Technician Task Force should be available for consideration by the Board to guide work on those two areas.

Looking back 3 years ago, few could have imagined where we would be as a Society today. Gazing into the looking-glass and beyond, it is perhaps even more difficult to predict the future in light of the COVID-19 pandemic and its far-ranging effects. The dedication and professionalism demonstrated by hospital pharmacy teams from leading the response to managing drug shortages and caring for patients in these challenging times has shown how essential our profession is to the health of Canadians. I am proud to have served as a presidential officer of this strong, resolute, and dedicated national society, and I am looking forward to seeing what we will accomplish in the years to come.

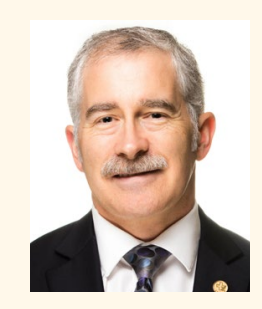

Douglas Doucette, BSc(Pharm), PharmD, FCSHP was, at the time of writing, Past President and External Liaison for the Canadian Society of Hospital Pharmacists (CSHP). As of October 17, 2020, he completed his 3-year term as a presidential officer of CSHP. 